\title{
PENGARUH PENGGUNAAN JENIS BAHAN BAKAR SOLA B20, DEXLITE B20 DAN PERTAMINA DEX TERHADAP OPASITAS, DAYA DAN KONSUMSI BAHAN BAKAR PADA INNOVA DIESEL COMMON RAIL
}

\author{
Cici Rosdiyanti ${ }^{1}$, Herman Mariadi Kaharmen ${ }^{2}$ \\ Program Studi Pengujian Kendaraan Bermotor \\ Politeknik Keselamatan Transportasi Jalan \\ Jalan Semeru No.3 Kota Tegal, Jawa Tengah 52125 \\ E-mail:cicirosdiyanti0309@gmail.com
}

\begin{abstract}
Abstrak
Bahan bakar yang saat ini digunakan adalah biosolar B20, dexlite B20 dan pertamina dex. Ketiga bahan bakar tersebut tampak sama namun memiliki sifat dan angka cetane yang berbeda. Pemakaian bahan bakar yang sesuai digunakan juga untuk memperoleh performa mesin yang tinggi, irit bahan bakar dan rendah emisi. Dalam penelitian ini menggunakan satu sampel kendaraan Kijang Innova Diesel Common Rail tahun 2005 dan dilihat perbandingan hasil opasitas, daya dan konsumsi bahan bakar terhadap tiga jenis bahan bakar dan lima variasi kecepatan yaitu dengan kecepatan $20 \mathrm{~km} / \mathrm{jam}, 40 \mathrm{~km} / \mathrm{jam}, 50 \mathrm{~km} / \mathrm{jam}, 70 \mathrm{~km} / \mathrm{jam}$ dan $90 \mathrm{~km} / \mathrm{jam}$. Pengolahan data pada penelitian menggunakan metode analisis deskriptif dengan melakukan uji two way anova menggunakan program SPSS. Untuk perbedaan hasil opasitas diukur menggunakan alat uji smoke tester, untuk perbedaan hasil daya diukur menggunakan chassis dynamometer, dan untuk hasil konsumsi bahan bakar menggunakan alat tes konsumsi bahan bakar. Hasil penelitian menunjukan bahwa bahan bakar biosolar B20 memiliki hasil ratarata opasitas terbesar yaitu 9,300\%, dexlite B20 sebesar 7,867\%, dan pertamina dex sebesar $5,667 \%$, dilihat dari hasil penelitian bahwa hasil rata-rata opasitas dari tiga jenis bahan bakar tersebut masih dibawah ambang batas yang telah ditetapkan oleh Keputusan Menteri Lingkungan Hidup No.5 tahun 2006, jika dilihat dari hasil daya bahan bakar pertamina dex yang memiliki hasil rata-rata daya paling bagus sebesar 7,847 hp, dexlite sebesar 7,540 hp, dan pertamina dex sebesar 7,300 hp, sedangkan untuk hasil rata-rata konsumsi bahan bakar diperoleh bahwa bahan bakar dexlite B20 lebih irit dibandingkan dengan pertamina dex dan biosolar B20. Dengan jumlah rata-rata untuk bahan bakar dexlite B20 sebesar 23,533 g/s, pertamina dex sebesar 23,600 g/s dan biosolar B20 sebesar 24,533 g/s.
\end{abstract}

Kata kunci: opasitas, daya, konsumsi bahan bakar

\section{PENDAHULUAN}

Pemakaian bahan bakar yang sesuai digunakan juga untuk memperoleh performa mesin yang tinggi, irit bahan bakar dan rendah emisi. Semua kendaraan mengeluarkan emisi, namun yang cukup membahayakan adalah emisi gas buang yang dihasilkan mesin diesel. Emisi dari mesin diesel memiliki implikasi nyata bagi kesehatan semua orang. Gas buang mesin diesel sangat banyak mengandung partikulat karena banyak dipengaruhi oleh faktor dari bahan bakar yang tidak bersih. Bahan bakar yang saat ini digunakan adalah solar B20, dexlite B20 dan pertamina dex. Solar B20 adalah bahan bakar diesel campuran minyak bumi (potroleum diesel) 80\% dengan bahan Fatty Acid 
Methyl Ester (FAME) sebesar 20\%. Pertamina Dex (singkatan dari "Diesel Environment Extra" memilik angka performa lebih tinggi dengan Cetane Number Minimal 53. Memiliki kandungan sulfur paling rendah di Indonesia yaitu 300 ppm. Dexlite B20 adalah bahan bakar minyak terbaru dari Pertamina untuk kendaraan bermesin diesel diIndonesia yang memiliki cetane number 51 dengan kandungan sulfurnya 1200 ppm (part per milion).

Daya maksimum didefinisikan sebagai kemampuan maksimum yang bisa dihasilkan oleh suatu mesin. Konsumsi bahan bakar disebabkan oleh perilaku pengemudi dalam berkendara, misalnya dalam melakukan percepatan atau memilih kecepatan. Dengan adanya teknologi pengontrol yang mampu mengatur campuran bahan bakar dan udara ke dalam ruang pembakaran secara cepat, tepat, proporsional sekaligus optimal maka penggunaan bahan bakar akan lebih irit atau lebih sedikit. Performance pada kendaraan bermotor dipengaruhi oleh kualitas bahan bakar dan sistem bahan bakar. Para pengguna kendaraan bermotor kurang menyadari bahwa spesifikasi rinci sangat menentukan gerak dan laju kendaraannya. Tujuan penelitian adalah sebagai berikut :

1. Untuk mengetahui pengaruh perbedaan antara hasil opasitas berdasarkan jenis bahan bakar solar B20, dexlite B20 dan pertamina dex pada kecepatan yang telah ditentukan.

2. Untuk mengetahui pengaruh perbedaan antara hasil daya berdasarkan jenis bahan bakar solar B20, dexlite B20 dan pertamina dex pada kecepatan yang telah ditentukan.

3. Untuk mengetahui pengaruh perbedaan antara hasil konsumsi bahan bakar berdasarkan jenis bahan bakar solar B20, dexlite B20 dan pertamina dex pada kecepatan yang telah ditentukan.

4. Untuk mengetahui bagaimana perbandingan penerapan biosolar (solar B20 dan dexlite B20) terhadap non bioslar (pertamina dex) dilihat dari opasitas, daya dan konsumsi bahan bakar.

\section{METODE PENELITIAN}

Penelitian eksperimen merupakan penelitian yang berusaha mencari pengaruh variabel tertentu terhadap variabel lain dengan kontrol yang ketat. Tempat penelitian dilaksanakan di PPPPTK (Pusat Pengembangan dan Pemberdayaan Pendidik dan Tenaga Kependidikan) BEO (Bidang Otomotif dan Elektronika) - VEDC (Vocational Education Development Center) Malang tepatnya digedung laboratorium teknik otomotif, yang berada di Jalan Teluk Mandar Tromol Pos No.5 Arjosari, Kec Blimbing , Kota Malang Jawa Timur 65126. Adapun alat dan

bahan yang digunakan dalam penelitian ini :

1. Chassis Dynamometer, digunakan untuk mengukur daya pada kendaraan yang di uji

2. Smoke Tester, digunakan untuk Mengukur hasil opasitas pada kendaraan yang di uji

3. OBD-II Scan Tool, digunakan untuk melihat APP pda kendaraan yang di uji

4. Alat Tes Konsumsi Bahan Bakar, digunakan untuk mengukur konsumsi bahan bakar yang digunakan dalam waktu 1 menit

5. Sabuk Penahan, digunakan untuk menjaga keamanan pada saat kendaraan di uji

6. Blower, digunakan untuk mendinginkan mesin kendaraan pada saat mesin kendaraan dinyalakan agar tidak terlalu panas 
7. Camera, digunakan untuk mendokumentasikan penelitian

8. Stopwatch, digunakan untuk mengukur waktu pada saat penelitian berlangsung

9. Kijang Innova Diesel Common Rail, merupakan sampel yang kendaraan yang uji 10. Solar B20, Dexlite B20 dan Pertamian Dex, bahan bakar untuk penelitian

Teknik atau metode pengumpulan data pada penelitian ini yaitu menggunakan motode observasi, studi literatur dan dokumentasi. Data yang terkumpul perlu di olah lebih dahulu dengan tujuan menyederhanakan seluruh data yang terkumpul menyajikan dalam susunan yang baik dan rapi untuk dianalisis. Teknik pengolahan data menggunakan komputerisasi program SPSS (Statistical Program for Social Science) 16.0 versi for Windows. SPSS yaitu suatu program komputer statistik yang mampu memproses data statistik secara tepat dan cepat, menjadi berbagai output yang dikehendaki para pengambil keputusan. Pada penelitian ini menggunakan uji Two Way Anova. SPSS adalah aplikasi yang digunakan untuk melakukan analisis statistika tingkat lanjut, analisis data dengan algoritma machine learning, analisis string, serta analisis big data yang dapat diintegrasikan untuk membangun platform data analisis.

\section{HASIL DAN PEMBAHASAN}

Tabel 1. Data Hasil dan Pembahasan Pada Opasitas

\begin{tabular}{clllllllll}
\hline KECEPATAN & \multicolumn{2}{c}{$\begin{array}{c}\text { OPASITAS } \\
\text { (SOLAR B20) }\end{array}$} & \multicolumn{3}{c}{$\begin{array}{c}\text { OPASITAS } \\
\text { (DEXLITE B20) }\end{array}$} & \multicolumn{3}{c}{$\begin{array}{c}\text { OPASITAS } \\
\text { (DEX) }\end{array}$} \\
\hline 20km/jam & 4 & 5 & 6 & 5 & 5 & 6 & 3 & 4 & 4 \\
$40 \mathrm{~km} / \mathrm{jam}$ & 4.5 & 5.5 & 5 & 4 & 5 & 4 & 3 & 4 & 5 \\
$50 \mathrm{~km} / \mathrm{jam}$ & 8 & 8.5 & 8 & 6 & 7 & 7 & 5 & 6.5 & 7 \\
$70 \mathrm{~km} / \mathrm{jam}$ & 8 & 9 & 9 & 6 & 7 & 8 & 6 & 6 & 6 \\
$90 \mathrm{~km} / \mathrm{jam}$ & 19 & 20 & 20 & 16 & 16 & 16 & 8.5 & 8.5 & 8.5 \\
\hline
\end{tabular}

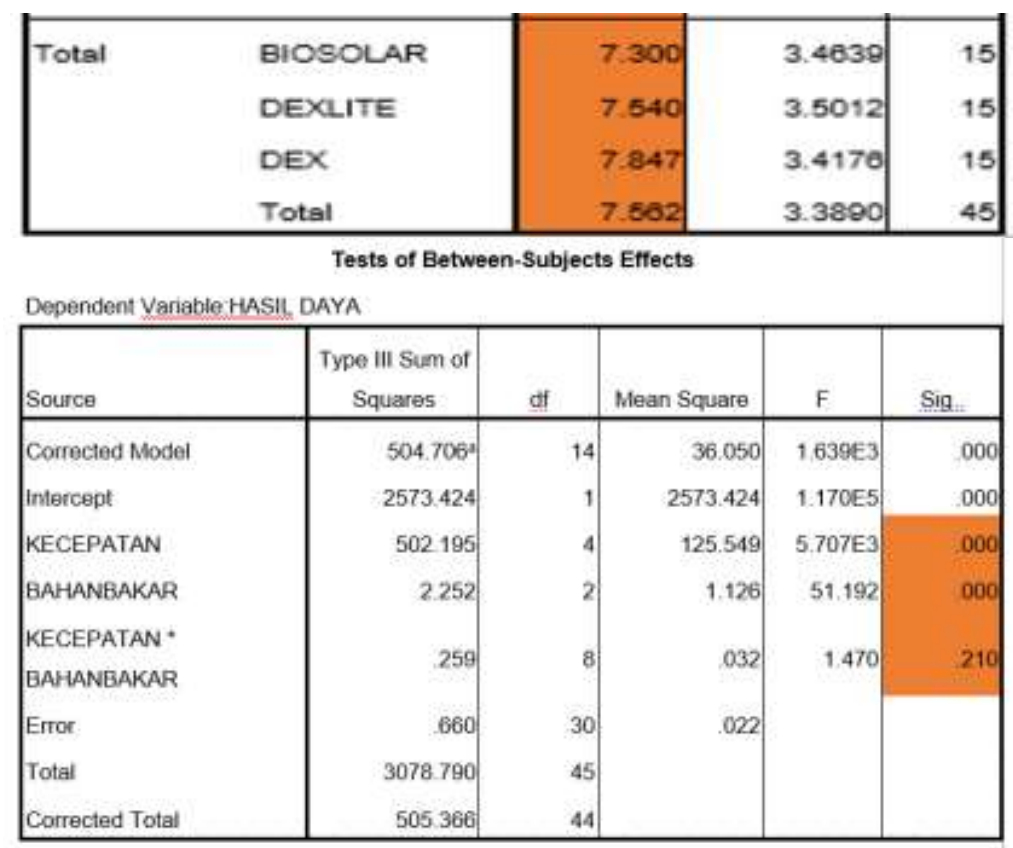

a. R Squared = ,999 (Adjusted R Squared $=, 998$ ) 
Pembuatan kesimpulan :

1. Diperoleh nilai sig. 0,000 <0,05, sehingga dapat disimpulkan bahwa "ada perbedaan" hasil opasitas berdasarkan variasi kecepatan. Atau Ho1 ditolak ha1 diterima.

2. Diperoleh nilai sig. sebesar $0,000<0,05$, sehingga dapat disimpulkan bahwa "ada perbedaan" hasil opasitas berdasarkan jenis bahan bakar. Atau Ho2 ditolak Ha2 diterima.

3. Diperoleh nilai sig. $0,00<0,05$, maka dapat disimpulkan bahwa "ada interaksi" antara variasi kecepatan dengan jenis bahan bakar dalam hasil opasitas kendraan bermotor. Atau Ho3 ditolak Ha3 diterima.

Tabel 2. Data Hasil dan Pembahasan Pada Daya

\begin{tabular}{|c|c|c|c|c|c|c|c|c|c|}
\hline \multirow{2}{*}{$\begin{array}{c}\text { KECEPATAN } \\
20 \mathrm{~km} / \mathrm{jam}\end{array}$} & \multicolumn{3}{|c|}{$\begin{array}{l}\text { OPASITAS } \\
\text { (SOLAR B20) }\end{array}$} & \multicolumn{3}{|c|}{$\begin{array}{c}\text { OPASITAS } \\
\text { (DEXLITE B20) }\end{array}$} & \multicolumn{3}{|c|}{ OPASITAS (DEX) } \\
\hline & 2.5 & 2.6 & 2.7 & 2.7 & 2.7 & 2.8 & 2.9 & 3.1 & 3.2 \\
\hline $40 \mathrm{~km} / \mathrm{jam}$ & 5.5 & 5.1 & 5.2 & 5.3 & 5.2 & 5.7 & 6.1 & 5.9 & 60 \\
\hline $50 \mathrm{~km} / \mathrm{jam}$ & 6.9 & 6.8 & 7 & 7.4 & 7.1 & 7.4 & 7.7 & 7.3 & 7.5 \\
\hline $70 \mathrm{~km} / \mathrm{jam}$ & 9.5 & 9.3 & 9.5 & 9.8 & 9.8 & 9.8 & 10 & 10 & 9.9 \\
\hline $90 \mathrm{~km} / \mathrm{jam}$ & 12.4 & 12.2 & 12.3 & 12.3 & 12.5 & 12.6 & 12.5 & 12.9 & 12.7 \\
\hline
\end{tabular}

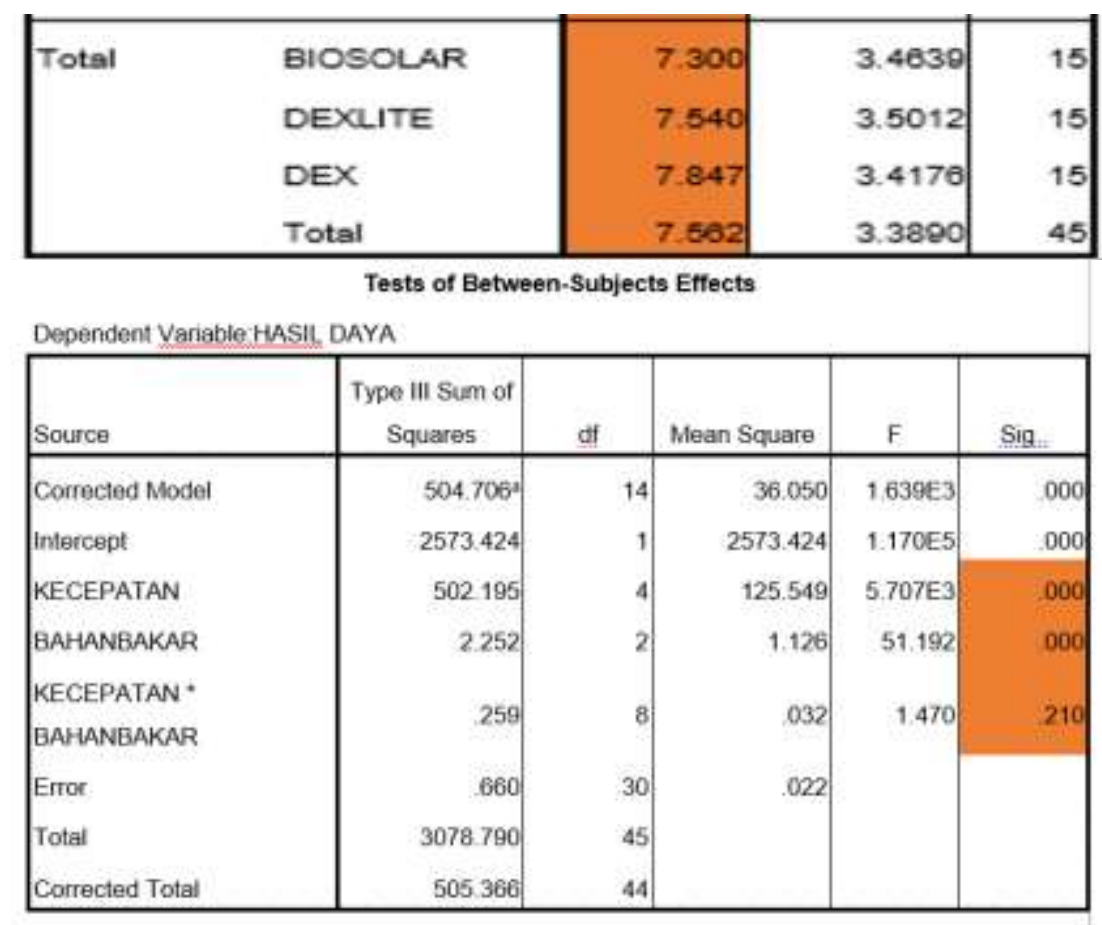

a. R Squared $=, 999$ (Adjusted R Squared $=, 998$ )

Pembuatan kesimpulan :

1. Diperoleh nilai sig. 0,000 <0,05, sehingga dapat disimpulkan bahwa "ada perbedaan" hasil opasitas berdasarkan variasi kecepatan. Atau Ho1 ditolak ha1 diterima. 
2. Diperoleh nilai sig. sebesar $0,000<0,05$, sehingga dapat disimpulkan bahwa "ada perbedaan" hasil opasitas berdasarkan jenis bahan bakar. Atau Ho2 ditolak Ha2 diterima.

3. Diperoleh nilai sig. 0, $210>0,05$, maka dapat disimpulkan bahwa " tidak ada interaksi" antara variasi kecepatan dengan jenis bahan bakar dalam hasil opasitas kendraan bermotor. Atau Ha3 ditolak Ho3 diterima.

Table 3. Data Hasil dan Pembahasan Pada Konsumsi Bahan Bakar

\begin{tabular}{|c|l|l|l|l|l|l|l|l|l|}
\hline KECEPATAN & \multicolumn{3}{|c|}{$\begin{array}{c}\text { OPASITAS } \\
\text { (SOLAR B20) }\end{array}$} & \multicolumn{3}{c|}{ OPASITAS } & \multicolumn{3}{c|}{ OPASITAS } \\
(DEXLITE B20) & \multicolumn{3}{c|}{ (DEX) } \\
\hline $20 \mathrm{~km} / \mathrm{jam}$ & 21 & 22 & 21 & 21 & 21 & 20 & 21 & 20 & 20 \\
\hline $40 \mathrm{~km} / \mathrm{jam}$ & 28 & 27 & 27 & 26 & 25 & 25 & 26 & 27 & 25 \\
\hline $50 \mathrm{~km} / \mathrm{jam}$ & 21 & 22 & 22 & 21 & 20 & 21 & 21 & 20 & 20 \\
\hline $70 \mathrm{~km} / \mathrm{jam}$ & 24 & 24 & 24 & 23 & 23 & 23 & 21 & 23 & 23 \\
\hline $90 \mathrm{~km} / \mathrm{jam}$ & 29 & 28 & 28 & 28 & 29 & 27 & 29 & 30 & 28 \\
\hline
\end{tabular}

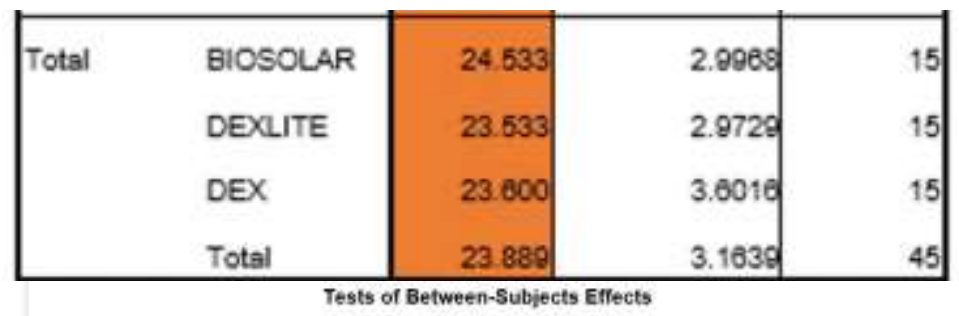

\begin{tabular}{|c|c|c|c|c|c|}
\hline Source & $\begin{array}{c}\text { Type III Sum of } \\
\text { Squares }\end{array}$ & $\mathrm{dt}$ & Mean Square & $\mathrm{F}$ & Sig. \\
\hline Corrected Modnl & 425,778 & 14 & 30.413 & $62.20 \mathrm{a}$ & .000 \\
\hline intercept & 25850.556 & 1 & 25890.556 & 5.253E4 & .000 \\
\hline KECEPATAN & 409.333 & 4 & 102.333 & 200.318 & .000 \\
\hline BAHANBAKAR & 8.378 & 2. & 4.689 & 9.591 & .001 \\
\hline KECEPATAN * & $7 \mathrm{cos} 1$ & a) & & & $t=1$ \\
\hline BAHANEAKAR & 1.007 & of & .803 & 1.800 & 175 \\
\hline Error & 14.667 & 30 & 490 & & \\
\hline Tolal & 26121.000 & 45 & & & \\
\hline Corrected Total & 440.444 & 44 & & & \\
\hline
\end{tabular}

a. $R$ Squarod $=, 967$ (Adjustod $R$ Squarod $=, 951$ )

Pembuatan kesimpulan :

1. Diperoleh nilai sig. 0,000 < 0,05, sehingga dapat disimpulkan bahwa "ada perbedaan" hasil opasitas berdasarkan variasi kecepatan . Atau Ho1 ditolak Ha1 diterima.

2. Diperoleh nilai sig. sebesar 0,001 <0,05, sehingga dapat disimpulkan bahwa "ada perbedaan" hasil opasitas berdasarkan jenis bahan bakar. Atau Ho2 ditolak Ha2 diterima.

3. Diperoleh nilai sig. 0, $115>0,05$, maka dapat disimpulkan bahwa "tidak ada interaksi" antara variasi kecepatan dengan jenis bahan bakar dalam hasil opasitas kendraan bermotor. Atau Ha3 ditolak Ho3 diterima. 


\section{PENUTUP}

\section{Simpulan}

1. Berdasarkan hasil dari descriptive statistics nilai rata-rata hasil opasitas yang berbahanbakar Solar B20 memiliki hasil rata-rata opasitas terbesar dengan nilai rata-rata 9,300\% berada diurutan pertama, kemudian diikuti oleh hasil opasitas yang berbahan bakar

2. Dexlite B20 dengan nilai rata-rata $7,867 \%$ dan Pertamina Dex sebesar $5,667 \%$. Berdasarkan hasil dari descriptive statistics nilai rata-rata hasil daya yang berbahan bakar Pertamina Dex memiliki hasil rata-rata daya terbesar dengan nilai rata-rata 7,847 hp berada diurutan pertama, kemudian diikuti oleh hasil daya yang berbahan bakar Dexlite B20 dengan nilai rata-rata 7,540 hp dan Solar B20 sebesar 7,300 hp.

3. Berdasarkan hasil dari descriptive statistics nilai rata-rata hasil konsumsi bahan bakar yang berbahan bakar Solar B20 memiliki hasil rata-rata konsumsi bahan bakar terbesar dengan nilai rata-rata $24,533 \mathrm{~g} / \mathrm{s}$ berada diurutan pertama, kemudian diikuti oleh hasil konsumsi bahan bakar yang berbahan bakar Pertamina Dex dengan nilai rata-rata 23,600 g/s dan Dexlite B20 sebesar 23,533 g/s.

4. Perbedaan hasil opasitas antara jenis bahan bakar biosolar (Solar B20 dan dexlite B20) dengan non biosolar (pertamina dex) yaitu sebesar 39\% pada bahan bakar Solar B20 dengan pertamina dex dan 27\% pada bahan bakar dexlite B20 dengan pertamina dex.

5. Perbedaan hasil daya antara jenis bahan bakar biosolar (Solar B20 dan dexlite B20) dengan non biosolar (pertamina dex) yaitu sebesar $7 \%$ pada bahan bakar Solar B20 dengan pertamina dex dan 4\% pada bahan bakar dexlite B20 dengan pertamina dex.

6. Perbedaan hasil konsumsi bahan bakar antara jenis bahan bakar biosolar (Solar B20 dan dexlite B20) dengan non biosolar (pertamina dex) yaitu sebesar 3,8\% pada bahan bakar Solar B20 dengan pertamina dex dan 0,3\% pada bahan bakar dexlite B20 dengan pertamina dex. Yang artinya bahan bakar dexlite B20 lebih irit $0,3 \%$ dibandingkan dengan bahan bakar pertamina dex.

\section{Saran}

1. Dari hasil kesimpulan diatas maka penulis menyarankan untuk kendaraan diesel Common Rail lebih baik menggunakan bahan bakar dexlite B20 karena jika dilihat dari hasil konsumsi bahan bakar dexlite B20 ini lebih irit 0,3\% dibandingkan dengan bahan bakar pertamina dex. Jika dilihat dari hasil daya bahan bakar dexlite B20 ini tidak jauh berbeda dengan bahan bakar pertamina dex hanya selisih 4\% saja. Dan jika dilihat dari hasil opasitas jenis bahan bakar dexlite B20 dengan pertamina dex hanya selisih $27 \%$ dan hasil opasitas dari bahan bakar dexlite B20 tidak ada yang melebihi ambang batas yang telah ditetapkan oleh Peraturan Menteri Lingkungan Hidup No.5 tahun 2006 sehingga untuk hasil opasitas masih berada di zona aman.

2. Pada tahun 2020 pemerintah berencana akan membuat bahan bakar solar B30, sedangkan berdasarkan hasil penelitian ini bahan bakar Solar B20 berada diurutan ke tiga dibawah dexlite B20 dan pertamina dex, sehingga penulis menyarankan sebaiknya pemerintah merencanakan untuk pembuatan bahan bakar dexlite B30 selain harga bahan bakar dexlite B20 tidak terlalu mahal untuk hasil opasitas, daya dan konsumsi bahan bakar juga tidak jauh berbeda dengan bahan bakar pertamina 
dex yang pada saat ini menduduki urutan pertama pada jenis bahan bakar untuk mesin diesel.

\section{DAFTAR PUSTAKA}

Keputusan Menteri Lingkungan Hidup No. 5 Tahun 2006 tentang Ambang Batas Emisi Gas

Buang Kendaraan Bermotor Dipetik juli 20, 2019, dari https://www.pertamina.com/industrialfuel/media/6796/biosolar.pdf

Dipetik juli 20, 2019, dari https://id.wikipedia.org/wiki/Dexlite

Dipetik juli 20, 2019, dari

https://www.pertamina.com/industrialfuel/media/20713/pertamina-dex.pdf

Andi. (2014). kerja mesin menggunakan metode fuel open throttle valve.

Ardhita Herdriarto, p. s. (2015). penggunaan bahan bakar solar dengan solar B20 terhadap performansi engine cummins qsk 45 c. bachtiar, v. s. (2017). mengetahui konsentrasi gas $\mathrm{CO}$, NO2 dan SO2 yang dilepaskan dari beberapa kendaraan roda empat saat kecepatan 0, 20, 40, 60, 80 km/jam.

Basyirun. (2008). proses pembakaran. cappenberg, a. (2017). pengaruh penggunaan bahan bakar solar, solar B20 dan pertamina dex terhadap prestasi motor diesel silinder tunggal.

Dange, k. d. (2014). solar B20 dianggap sebagai bahan bakar biodegradable.

Ihwan Haryono, I. U. (2016). simposium nasional RAPI XV FT UMS. emisi smoke dan keausan logam pada pelumas kendaraan truk berbahan bakar biodoesel duapuluh persen.

Karnowo, w. d. (2008). definisi bahan bakar.

Kurniawan, i. (2005). perngaruh daya dan torsi.

Murdianto, i. (2016). mengetahui perbedaan performa (daya, torsi dan konsumsi bahan bakar) menggunakan injektor standar dan injektor racing dengan bahan bakar pertamax dan pertamax plus pada sepeda motor yamaha $v$-xion.

Octavia, r. z. (2011). pembuatan dan uji kualitas bahan bakar alternatif (biodiesel) dari minyak kelapa .

Priyastama. (2017). Buku Sakti Kuasai SPSS. Jogjakarta: START UP.

Sudibyo. (2011). pengaruh daya dan torsi motor.

Wibisono. (2007). biosolar dari minyak sawit, minyak kelapa, minyak jarak. 